\title{
La recepción temprana de Marcel Proust en el espacio de revistas culturales argentinas de los años veinte
}

\section{The Early Reception of Marcel Proust in the Space of Argentinian Cultural Journal of the Twenties}

\section{Resumen}

Este trabajo analiza el fenómeno de lectura de En busca del tiempo perdido, de Marcel Proust, a partir de la centralidad que cobró su recepción en un arco muy diverso de publicaciones literarias y culturales aparecidas en Buenos Aires en la década de 1920. Analiza el modo en que a través de éstas las diversas colaboraciones encontraron en la lectura de esta obra distintos motivos para definir una sensibilidad emergente y, por otro lado, para pensar el lugar del arte en nueva cultura urbana y masiva. En este sentido, se describen dos claves de lectura, espiritualista y de apertura a la experimentación narrativa, que junto a un interés por teorizar acerca de la novedad en el arte, confirman disposiciones vanguardistas que van más allá del grupo nucleado en torno a la revista Martín Fierro (1924-1927). Por último, el análisis se detiene en la apropiación específica de algunas ideas de Proust desde una experiencia cultural periférica respecto de los centros europeos.

Palabras claves

Recepción de Marcel Proust, publicaciones culturales de Buenos Aires, vanguardia y modernización cultural en la década de 1920, historia de las ideas críticas.

\begin{abstract}
This article analyzes Marcel Proust's $\grave{A}$ la Recherche du Temps perdu reading fenomenous, starting from its central reception in a varied archo of literary and cultural reviews in Buenos Aires by 1920. It examines how the diferent articles hace found in this novel some ways to
\end{abstract}


CATEDRAL TomAdA: Revista de crítica literaria latinoamericana / Journal of Latin American Literary Criticism

La recepción temprana de Marcel Proust en el espacio de revistas culturales argentinas de los años veinte

define an emerging sensibility and to think urban masive culture. In this way, this work describes two reading keys, one sipirtualist and the other one opened to narrative experimentation. In relation to an interest in theorize, they confirm am avant-garde disposition which goes over the classical avant-garde group of Martin Fierro review (19241927). Finally, this study focuses on the specific apropriation of one of Proust's ideas, by a periferical cultural experience, in regard of European centers.

Keywords Marcel Prous's Reception, Cultural Reviews in Buenos Aires, Avant garde and cultural modernization by 1920, History of Critics Ideas.

En ocasión de los catorce años de la muerte de Marcel Proust (1871-1922), el historiador Julio Irazusta recordaba en un artículo para La Nación de Buenos Aires el impacto que el escritor francés había tenido entre los jóvenes de su generación:

Siempre es una aventura releer a un contemporáneo, después de transcurrido cierto tiempo desde el primer entusiasmo por su obra, sobre todo cuando dichos entusiasmos fueron juveniles.[...] Si yo no escribí un libro sobre Proust, ni manifesté públicamente mi juicio, participé del entusiasmo que por él sintieron muchos de mis compañeros de generación, y no de los últimos. (1)

En la Argentina de los años veinte, semejante interés por las novelas de Proust significó - tal como veremos- un verdadero fenómeno cultural, que fue revelador del afán de renovación que caracterizó las búsquedas intelectuales y artísticas de aquellos tiempos de modernidad cultural y social y de desarrollo de la cultura de masas. En efecto, los sucesivos tomos de la Recherche du temps perdu no recibieron meros comentarios en los suplementos literarios de la prensa, de acuerdo al imperativo de actualización que se buscaba en las novedades europeas, sino que fueron intensamente leídos en forma simultánea a su aparición en Francia, en su lengua original, por los jóvenes escritores y universitarios procedentes de los más distintos ámbitos culturales porteños: desde quienes eran cercanos a las 
vanguardias hasta narradores vinculados al grupo literatura social conocido como de Boedo, estudiantes o recién graduados más o menos implicados en la renovación intelectual articulada en torno a la reacción antipositivista que alimentó en parte el movimiento de la Reforma Universitaria $1918 .{ }^{1}$ Tal interés también se comprueba en otras manifestaciones públicas (si seguimos las palabras de Irazusta) tales como conferencias organizadas por distintos ámbitos culturales porteños, que luego dieron lugar a dos de los artículos publicados sobre Proust. ${ }^{2}$

En este trabajo intentaré demostrar que el principal canal de recepción de los sucesivos tomos de En busca del tiempo perdido en Buenos Aires no fueron determinados intermediarios culturales, sino las propias revistas (literarias y de filosofía), que encontraron en la lectura de esta obra distintos motivos para definir una sensibilidad emergente y, por otro lado, para pensar el lugar del arte en nueva cultura urbana y masiva. Esta situación se comprueba en la diversidad de jóvenes intelectuales que se ocuparon de la obra, y especialmente en el tipo de escritos publicados, que se leen como el resultado de un estudio detenido, de un ejercicio de la crítica antes que escritura periodística. Luego de repasar las dos claves de lectura principales en que es posible analizar los sentidos en que se leyó la obra de Proust y su relación con los proyectos editoriales de las distintas publicaciones porteñas, intentaremos indagar, en términos de recepción, los modos en que los escritores locales se apropiaron de Proust.

\section{Una clave de lectura espiritualista}

Una de las claves de lectura de la obra de Proust se dio en el marco de la reacción antipositivista que caracterizó a gran parte del movimiento juvenil de la

${ }^{1}$ Cf. Cuadro adjunto sobre la circulación de la obra y sus traducciones, y los artículos referidos a la obra de Proust.

${ }^{2}$ Es el caso de "Marcel Proust", de Juan P. Ramos, conferencia con que se inauguró el Instituto Popular de conferencias (dependiente del diario La Prensa), el 30 de abril de 1926. (Verbum n66: 227, n.1), y de "Introducción a Marcel Proust" de Roberto Mariani, un escrito leído el 9 de abril de 1927 en la Asociación de Artistas y escritores La Peña (Nosotros, a. 21 t. 56: 16). 
Reforma Universitaria. En lo conceptual, éste se expresó en una búsqueda de renovación filosófica abierta al idealismo, la metafísica y las corrientes espiritualistas tales como el pensamiento de Bergson, y que fuera capaz de propiciar, contra el llamado "utilitarismo", la restauración de los elementos espirituales como aspectos decisivos de la existencia humana. ${ }^{3}$ De hecho, Proust podía leerse desde el bergsonismo ${ }^{4}$ o como confirmación del esteticismo concebido como amparo de la "cultura" frente a las fuerzas materialistas y cientificistas. Mas aún, la literatura contemporánea se ofrecía como la prueba de ese fondo "oscuro" e "inalcanzable" que no había abandonado a los humanos, y la expresión de la "nueva sensibilidad" y de la "deshumanización del arte" que habían sido definidas por José Ortega y Gasset.

De este modo, la propia incorporación, por parte de las revistas de las nuevas generaciones tales como Verbum (1912-1942), Síntesis (1927-1930), Valoraciones (1923-1928), o Fiesta (1927-1928), podía leerse como un desarrollo en acto de la producción crítica y filosófica local, y una prueba de la propia vitalidad de este pensamiento. Proust representó entonces, para los jóvenes antipositivistas, un motivo para ensayar ideas sobre el arte del presente, tanto como sobre la cuestión del "subjetivismo", según los términos de una de estas colaboraciones que fue publicada en Verbum, la revista del Centro de Estudiantes de la Facultad de

\footnotetext{
${ }^{3}$ Ver entre otros: Terán (2008), Bustelo (2015) y Ruvituso (2015).

${ }^{4}$ A propósito del bergsonismo en América Latina, Alain Guy (1963) ha observado una clave de lectura introspectiva, incluso mística de la lectura de Bergson. Me interesa destacarlo más allá de una caracterización en términos de lecturas de este filósofo correctas y originales, frente a otras, periféricas, que no lo serían (siendo "contrasentidos"), porque dan cuenta de la gravitación del bergsonismo en relación con las lecturas de Proust: "Posiblemente, la mayoría de los bergsonianos ibero-americanos haya tomado sobre todo de Bergson su reparo frente a cualquier « filosofía de la cosa » (para retomar una expresión de Renouvier) y su llamado a las «filosofías de la persona » y también su rehabilitación de la vida interieur, incluso de la experiencia mística, antes que sus pacientes y admirables análisis de filosofía científica sobre la afasia y sus causas, sus sutiles páginas en Matière et mémoire acerca de la función del cerebro como órgano del recordar -y no de la conservación- de los recuerdos, o también los arduos capítulos sobre la relatividad einsteiniana, en Durée et simultanéité y las páginas de elevada meditación biológica presente en varias partes de L'Evolution créatrice. Puede que, incluso, por momentos, se hayan cometido algunos contrasentidos irracionalistas, afectivistas y vitalistas, respecto de esta doctrina que resulta sin embargo tan puramente fiel a la tradición francesa de la razón serena y clara". (139La cursiva es mía). Sobre la recpeción de Bergson en Argentina, ver también Sosa (2018).
} 
Filosofía y Letras de la UBA. ${ }^{5} \mathrm{O}$ también para demostrar que la estética, en un sentido mucho más amplio que unos simples recursos formales, debía guiar la acción intelectual de la juventud. Así, el artículo "Marcel Proust” de Juan P. Ramos, aparecido en dicha publicación con motivo de la aparición de dos nuevos volúmenes de la novela proustiana, ofrecía un análisis extenso y pormenorizado de quien se presentaba sin "ningún título" pero autorizándose a escribir "en razón del amor que le profesa[ba]. Proust pertenece a todo hombre que haya buscado alguna vez en la complejidad de su corazón la impulsión oculta que determina la realidad incoherente o lógica de un acto" (Ramos 227). En línea con las preocupaciones “esteticistas" de la revista en esta etapa, el artículo sitúa el empeño proustiano "en reconstruir lo inasible de las impresiones fugitivas que despiertan las horas al pasar por el alma en el torbellino desconcertante que es la vida espiritual" y explica de este modo que su "fama" europea, pese a una "prosa rebelde y revesada", haya hecho de su nombre el "más universalmente difundido en los círculos de la cultura superior del espíritu" (250). Además de exhibir un conocimiento de los escritos críticos franceses sobre Proust (en las referencias a Crémieux o a Rivière, críticos de la Nouvelle Revue Française), Ramos se detiene en el estilo literario como una “consecuencia de la manera de ver" (232). Esta idea que, por cierto, el propio Proust desarrolló en su novela, permite a Ramos conectar aspectos estrictamente literarios con un orden espiritual que le otorgaría todo su sentido al arte, de allí que enseguida concluya que "su estilo es así un esfuerzo terrible para traducir, a la manera de una anotación musical, la vida entera del alma en palabras" (232). Como se ve, se trata además de desarrollar una evaluación crítica del arte proustiano, tal como puede advertirse en este comentario:

${ }^{5}$ Natalia Bustelo (2015) afirma que después de que Bermann dejara la dirección de Verbum para asumir la presidencia de dicho Centro, la revista quedó a cargo de la lista universitaria rival (Jacinto Cuccaro y Juan Probst). En el año de aparición de los artículos sobre Proust, primaba ya en la revista la recepción del idealismo neokantiano y la asociación de la actividad filosófica con una reflexión abstracta, que se enfrentaba "a la 'condición social' del hombre propuesta tanto por Ingenieros como por Gregorio Bermann y Alberto Palcos.” (Bustelo: 144). La autora mostró cómo Verbum fue poco a poco omitiendo cuestiones gremiales del Centro de Estudiantes y los debates sobre la cuestión social, asumidos por los grupos más politizados de la Reforma. 
Un ser, una cosa, una acción, no son nada mientras no penetran en una de las proyecciones afectivas de su vida. En el instante en que siente, cuanto existe en el mundo desaparece o se pone a acompañar su sentimiento, baldío de toda significación esencial. El mérito de Proust consiste en haber escrito un libro enorme para exhibir el subjetivismo de la vida en el absoluto impudor objetivo de una obra de arte. Jamás nos engaña vistiéndose con el disfraz de las mentiras convencionales. Todos sentimos más o menos de esa manera, salvo cuando hacemos literatura o filosofía. [...] A cada momento, su pensamiento, en estado emocional, traduce la inexistencia independiente de la naturaleza. (Ramos 242)

Aquí el interés por Proust no se centra en la novedad artística, que presupone la creencia en la revolución permanente en el arte -aunque Ramos señale la invención proustiana de un género literario nuevo en la elección de "una novela sin argumento, sin peripecias, sin ordenación lógica, sin principio ni fin” (248). Las innovaciones formales (y emite reservas sobre su "desproporción") se interpretan ante todo como confirmaciones de la sospecha de un orden espiritual que regiría la vida de los hombres y que precisamente, la literatura y el arte serían capaces de revelar.

Esto mismo aparece en Síntesis, una revista de cultura que reunió a universitarios que ya contaban con una trayectoria en la Universidad (el filósofo Coroliano Alberini, el historiador Emilio Ravignani, o el arquitecto Martín Noel, su segundo director, entre otros) y que mostró una apertura hacia las vanguardias literarias y el arte contemporáneo (colaboraron Jorge Luis Borges y Guillermo de Torre, entre otros). En el n $n^{\circ} 17$ de octubre de 1928, "Variaciones sobre Marcel Proust", Mario Pinto observa así que "Proust descubre hechos de conciencia inadvertidos", y exalta la creación artística proustiana como don superior, en tanto “obra inspirada en el fervor artístico" (215), a través de la cual Proust "toca, entre el fárrago de lo accesorio, lo esencial" y "realiza esa 'cuarta dimensión' que 
Bergson pedía para el arte" (218), por escribir no en el espacio sino en el tiempo. El autor cierra su afirmación según la cual "es la visión penetrante del artista que sabe colocarse en lo que Bergson llama duración pura" (217) transcribiendo directamente un fragmento del Ensayo sobre los datos inmediatos de la conciencia.

Ahora bien, otros señalamientos presentes en estas revistas vinculadas con la renovación espiritualista posterior a la Reforma Universitaria acercan la lectura de la novela al freudismo, por un lado, y a la psicología, por el otro. En Verbum, por ejemplo, Ramos califica su "potencia de análisis" del "mundo de los sueños" como "superior a la misma escuela de Freud" (247). También encuentra en la novela de Proust una afirmación de la "impoten[cia] [de la] razón para vencer al terrible egoísmo sensual de dominación" (249) o de la "verdad de que la subconciencia [sic] afectiva es la única fuente de donde mana la vida del ser". En este sentido, "Sus más de tres mil páginas compactas y largas contienen la más prodigiosa introspección que se haya realizado jamás en literatura” (228). Por su parte, Mario Pinto destaca, en el artículo ya citado de Síntesis, los "volúmenes extensos y sinuosos como la vida que reflejan, que es la vida del yo interior, del yo profundo" (215).

La figura del novelista, que tras su muerte reciente se encontraba en la cumbre de su consagración, ofrecía a los jóvenes de otra publicación, la revista Fiesta, animada por un grupo de jóvenes abogados con inclinaciones nacionalistas y católicos, pero abiertos al arte moderno, un compendio de ideas generales sobre arte y literatura. En efecto, Proust les permitía construir rumbos posibles para la literatura, basados en el credo del arte interior y la introspección como una "nueva manera de interrogar la conciencia”, según había sintetizado Jacques Rivière ${ }^{6}$ en el número de homenaje a Marcel Proust de la N.R.F ( $\mathrm{N}^{\mathrm{o}}$ 112, enero de 1923: 186),

${ }^{6}$ Gisèle Sapiro (140) observa que en Francia fue Jacques Rivière quien contribuyó a introducir en el lenguaje crítico el dualismo freudiano de lo consciente e inconsciente. Nos consta, en la revista, que los editores conocían los escritos de Jacques Rivière, pero es posible pensar que el interés por seleccionar esa única lectura, entre las demás, nos habla de la apertura teórica del grupo, que sin duda puede relacionarse con su posición periférica, menos atada a fijar lecturas en relación con la tradición literaria francesa. Además, Seeber se refiere a la sexualidad, un aspecto que no es abordado por Rivière centralmente. 
acercando a Proust y Freud como pensadores que habían "inaugurado" esa línea. En este sentido, el joven abogado Arturo Seeber observaba en "Proust y el momento actual" (Fiesta $\left.\mathrm{n}^{\circ} 4\right)$ que

Proust estudia ciertos órdenes de movimiento mentales, y en esa misma independencia que le impide dejarse dominar por las ideas aceptadas, lo hace infalible en la elección de los temas que más importancia tienen en la formación de las mentalidades contemporáneas. Con penetración pocas veces alcanzada, su investigación abarca los asuntos más variados y complejos: el esnobismo, hasta sus menores detalles; la sexualidad -en lo que coincide muchas veces con Freud, sin llegar a su exclusivismo-; las artes, que considera como manifestaciones de lo más profundo del ser traducidas por la creación del artista; la cerebralidad de sus personajes; el amor subjetivo [...]; los trastornos de la memoria y las intermitencias del corazón $[\ldots] .(13)$

A esta veta introspectiva que Fiesta coincide en atribuir a Proust, y a la que suscribe en su diagnóstico sobre el arte actual, los editores suman un impulso "trascendente" que no puede dejar de leerse, en el contexto de los años veinte, en relación con el impacto de la vanguardia martinfierrista, pero también como una respuesta ante otras formas de la novedad que provenían de la cultura de masas en expansión. Como hemos visto, términos como "tendencia introspectiva" (Fiesta no4: 9), o "introspección", la idea de que el arte actual ofrecía formas intensas y superiores de exploración del yo, constituían un auténtico "rumor intelectual" (Bourdieu) en aquella década que ha sido recordada como de intensa actividad cultural.

Otra revista, esta vez claramente entroncada con el positivismo, como fue la Revista de Filosofía (1915-1929) dirigida por el psiquiatra y sociólogo José Ingenieros, también dedicó un artículo a Marcel Proust y se detuvo en el "estudio 
introspectivo". ${ }^{7}$ El hecho de que el joven psiquiatra Aníbal Ponce, co-director de la misma, escribiera un artículo al autor de la Recherche en esa revista cientificista pone en evidencia la preponderancia de Proust entre los jóvenes de la nueva generación, que llevaba a estos editores a intervenir en las discusiones en torno a esta obra, lo cual se enmarca a su vez en la disputa filosófica con los jóvenes neokantianos de la revista Verbum, o de Valoraciones ${ }^{8}$ (Bustelo).

Tal como hemos analizado, en éstas últimas, al igual que en Fiesta, la lectura de Proust era objeto de una apropiación de tipo identitaria, que motivaba el ejercicio de la crítica y del pensamiento en una clave subjetivista e introspectiva y contribuía a consolidar un programa de intervención espiritualista en el incipiente campo de la filosofía.

\section{Nuevos desarrollos para la novela}

Los modos de leer a Proust como un objeto de reflexión y de estudio también se advierten entre los escritores de los años veinte. Estas lecturas, tal como adelantamos, formaron parte de intercambios colectivos, dentro de las revistas que mencionamos, y también en conferencias dictadas en ámbitos culturales diversos, tales como la Asociación La Peña o el Instituto Popular de conferencias-propiedad del diario La Prensa. En el primer caso, la relación con Proust no solo se dio a través de artículos sobre su novela sino en alusiones a la producción intelectual en

7 "No conozco estudio introspectivo que haya desmenuzado de modo tan sutil el complicado engranaje del recuerdo. Cierto es que la psicología científica se ha apartado de las maneras tradicionales de la psicología literaria y [...] en el momento actual, nada tienen en común. [...] Y por lo que respecta al autor de la Recherche du temps perdu, puede decirse que ha construido con la sola ayuda del análisis interior una verdadera 'suma' del recuerdo". [...] Quiero señalar la importancia primordial concedida a las sensaciones del gusto y el olfato en esa resurrección laboriosa del pasado" (213). El artículo se cierra con una explicación científica de las razones por las que "Proust ha visto en la sensación olfactiva la última y mejor reserva del pasado: la fibra misteriosa que, cuando todas nuestras lágrimas parecen agotadas, encierra todavía el secreto del llanto" (217).

${ }^{8}$ Esta publicación reproducía una breve evocación de Proust a cargo de Alfonso Reyes en el último número de su aparición. En ese mismo número aparecía una separata con la Introducción a la metafísica de Henri Bergson, traducida al español, como un último obsequio a los lectores. 
torno a su obra, las que pueden interpretarse como formas de filiación respecto de su poética, que responden además a una intención de participar en un diálogo universal de ideas, tal como se observa en el número inaugural (y único) de Libra, una publicación porteña de fines de $1929 .{ }^{9}$ En efecto, en una pastilla de las últimas páginas, titulada "PROUST EN AMÉRICA", los editores Leopoldo Marechal y Francisco Bernárdez, dos antiguos integrantes de la revista vanguardista Martín Fierro, se referían a un libro crítico sobre Proust de Léon Pierre-Quint, ${ }^{10}$ recientemente publicado en París, para señalar la "copiosa bibliografía sobre la literatura extranjera relativa a Proust", y la incompleta información respecto de España y América Latina:

Y como antes [Quint] ha manifestado su deseo de que los lectores mismos le ayuden a subsanar las omisiones para una edición posible, vale la pena que los escritores de Hispanoamérica, en interés propio, acudan a llenar los vacíos de la bibliografía proustiana. LIBRA publicará regularmente las informaciones que se le remitan. (87)

Luego de señalar errores de información en el libro de Quint, los editores anuncian que ya han "comunicado a Pierre-Quint las siguientes noticias" (88). Por último, invitan a una "colaboración de nuestros lectores" en esa tarea, creando así una comunidad de pares, casi como coeditores de la publicación pues de hecho, informan que la lista de artículos que presentan se realizó "gracias al auxilio de los autores interesados y de las revistas que aquí mencionamos". La nota de Libra encabezaba una lista de "bibliografía" sobre Proust que incluía a los argentinos y a los latinoamericanos, mostrando de paso los vínculos con revistas del continente (Social de La Habana y Contemporáneos de México). Me interesa destacar, además, el gesto de participación "igualitarista" de los editores en la reflexión sobre

\footnotetext{
${ }^{9}$ Publicación disponible en el Archivo Histórico de Revistas Argentinas, http://www.ahira.com.ar.

${ }^{10}$ Quint había sido amigo de Proust. Fue luego director de Éditions Sagittaire, que publicaron a los Surrealistas (en particular, el Manifiesto de André Breton).
} 
literatura contemporánea europea, en este gesto de completar vacíos y corregir errores (tales como la autoría de la traducción de Du coté de chez Swann atribuida a José Ortega y Gasset y no a Pedro Salinas), que se presenta como una "respuesta a Quint" desde este continente.

En el caso de Martin Fierro (1924-1927), la única referencia al novelista francés aparece en el nº de mayo de 1924, con la publicación la "Oda a Proust" de Paul Morand traducida por HC [Héctor Castillo, seudónimo de Ernesto Palacio en la revista]. Esta inclusión, tomada del libro Lampe à arc (1919), resalta más la modernidad del poema de Morand que a Proust, pero se trata de un poema admirativo, además de ser un homenaje porque en sus versos se pone en escena la visita al escritor en el mismo presente en que sucede, a medida que el poeta va ingresando en el (mítico) cuarto de Proust.

Con respecto a las conferencias, una de ellas, titulada "Introducción a Marcel Proust", fue pronunciada por uno de los jóvenes escritores vinculados al grupo de Boedo, Roberto Mariani. Al mes siguiente, apareció publicada en el tomo XVI de 1927 de la revista Nosotros, junto al artículo "Por el camino de Proust", firmado por Max Dickmann, un escritor socialista también vinculado a la revista Claridad y al grupo de Boedo. ${ }^{11} \mathrm{Al}$ igual que los ensayos de las revistas de filosofía, ambos artículos dan cuenta de un conocimiento de los debates europeos, pues no solo se limitan a citar a críticos franceses contemporáneos sino que evalúan dichos análisis, y señalan por ejemplo los "motivos que no han sido explotados todavía" por la crítica (Mariani 17). Así, el hecho de que los autores de estos artículos fueran jóvenes escritores que seguían una concepción social de la literatura confirma los análisis que en las últimas décadas han señalado que la opción por el realismo en literatura no implicó que fueran ajenos al proceso de renovación vanguardista que

\footnotetext{
${ }^{11}$ Max Dickmann (1902-1991) fue un escritor, crítico literario y militante socialista. Entre la década del Treinta y el cuarenta fue subdirector de la Novela Semanal (entre 1935 y 1936) y publicó varias novelas (Gente, Madre América, Corazón al viento, Los días oscuros y Los frutos amargos y Esta generación perdida). Trabajó en la editorial de Santiago Rueda, el editor de los últimos tomos de En busca del tiempo perdido, y publicó en ellos una presentación de la novela de Proust.
} 
se desarrolló en la década del veinte. ${ }^{12}$ En este sentido, el estudio concreto de nuevas formas narrativas como la de Proust confirma la apertura respecto de la experimentación formal y de las vanguardias europeas, y prueba que esta no fue exclusiva de la vanguardia martinfierrista. Resulta significativo, además, que estos jóvenes aspirantes a escritor eligieran Nosotros, la revista de sus mayores y ya consagrada, por eso mismo alejada de las disputas de los años Veinte, para exponer sus lecturas críticas y reflexiones de orden teórico. En este sentido, la publicación en la revista Claridad, más conservadora en materia de narración realista, parecía improbable.

La lectura y el estudio de Proust, por parte de Roberto Mariani y de Max Dickmann, fueron entonces una ocasión para desarrollar en la escritura crítica, reflexiones inexploradas sobre la novela. Les permitieron articular valores en torno al arte de escribir y extender así los límites de la narrativa. Esto indica una tendencia a la teorización en materia literaria que confirma la flexión renovadora de los boedistas, en el mismo sentido que otras formaciones vanguardistas. Se trataba de una concepción del arte nuevo entendido como "originalidad" y basada en la experimentación formal, en ruptura con la tradición. Ambos artículos revelan además un grado ponderable de formación letrada en estos jóvenes de origen inmigrante, si se tienen en cuenta sus referencias específicas a la tradición crítica francesa en torno al clasicismo como conjunción de la "claridad, orden y medida", o a las relaciones entre estilo y medio establecidas por "el método de Taine" (Mariani 18). Frente a esta descripción de lo dominante, Mariani expone, con tanteos y modalizaciones, una interpretación del "estilo" de Proust: "Aunque más tarde demostraré que no es oscuro, ni abstruso, ni desordenado, conviene establecer ya mismo que Marcel Proust no entronca en la tradición francesa clásica" (18). ${ }^{13}$

\footnotetext{
${ }^{12}$ Ver, al respecto Candiano y Peralta (2007), Porrúa (2007), Bosoer (2012) y García Cedro (2012), entre otros.

${ }^{13}$ Además, se advierte esta inflexión teórica, cuando Mariani va evaluando los "procedimientos" de análisis; "con este procedimiento, es decir, explicar un aspecto artístico por circunstancias materiales, físicas, raciales, geográficas, podemos llegar a uno de los más curiosos problemas que Proust despierta: hasta dónde es francés el autor de Albertine". (...) "Con el método de Taine no resolvemos el problema del estilo pues en verdad la escritura de Proust es abigarrada y hasta antifrancesa". "Sus contemporáneos se resistían a leerlo..." (18).
} 
Su atención crítica se detiene en dos aspectos que revelan un cierto alejamiento respecto de la tradición naturalista de la novela, y más aún, una afinidad con el vanguardismo: la complejidad (en las antípodas de la pedagogía) y la novedad. En primer lugar, entonces, Mariani insiste en la exigencia que requiere al lector el estilo "francamente duro, complicado, difícil" (18) del novelista francés: "Marcel Proust exige a los lectores un indiscutible sacrificio para que puedan entrar en sus dominios" (20). Aquí leemos una sugestiva autoimagen de escritor pobre (y recién llegado a la cultura), pues Mariani lo compara con el esfuerzo material que significaba, en su propia infancia ("para nosotros, niños de vacías escarcelas"), el pago de la "enorme suma de cinco centavos" que era necesario para acceder al "mundo de bellezas del circo" (19).

En segundo lugar, para explicar el "encanto", Mariani no solo señala el efecto inesperado de la escritura proustiana sino que la explica en relación con un trabajo sobre la lengua literaria y por la experimentación técnica:

¿Es el estilo que, como hemos visto, reúne todas las condiciones que más bien lo afearían? La sorpresa agradable la provoca la novedad; Marcel Proust es nuevo, (I) nos ofrece aspectos nuevos de la realidad, y llega a adivinaciones psicológicas que a veces nos conturban con su precisión. Y todo ello en una prosa nueva, en un modo de decir creado por él para su uso personal. Él se creó su instrumento para sonar su música también creada por él. El encanto pues, está en lo que dice y en cómo lo dice. (20)

Hay aquí un hecho significativo que evidencia un indirecto modo, por parte de escritores más marginales, de participar de la reflexión en torno a la renovación literaria y más aún, de disputar la legitimidad para abordar determinados problemas literarios en Buenos Aires, en este caso, los debates sobre las vanguardias, hegemonizados por la formación martinfierrista. Esto se advierte en el propio hecho de que Mariani nombre la vanguardia, en su intento por caracterizar la novedad de Proust, llamando la atención, en una nota a pie, sobre el carácter vanguardista de 
Proust. A esto se suma una velada alusión a Martín Fierro, cuando menciona la "Oda a Proust" de Paul Morand, ${ }^{14}$ que precisamente había sido publicada por esta revista porteña (y fue la única referencia al escritor aparecida en dicha publicación):

(I) Marcel Proust goza de simpatías numerosas e incondicionales en la actual vanguardia literaria francesa. Recuérdese la oda de Paul Morand. Y es que en su obra realiza postulados de vanguardia, principalmente cuando enfoca la realidad desde puntos de vista novedosos, extraños. (20)

Más aún: para demostrar el especial efecto de los detalles en Proust, que al adquirir el "don del movimiento y de la vida" (21) lograban ingresar en nuestra "realización vital" (21), Mariani los compara con Gómez de la Serna, uno de los escritores predilectos de martinfierristas. Con estos gestos, Mariani designaba a éstos últimos como interlocutores (legitimándose en ese gesto, como interlocutor válido) pero esta vez, abandonaba el tono polémico y lo suplantaba por la prosa crítica y el saber específico. Por eso su atención está puesta en el "procedimiento" y sus efectos (el "asombro y deslumbramiento" 18). El modo de intervención a través de la teorización se observa también en las conceptualizaciones de la prosa proustiana, que lo llevan a caracterizarla en términos de una combinación acertada entre "minucia" y "composición, arquitectura", o "los complicados paisajes, las escenas completas justificadas por sucesos anteriores y por la psicología de los personajes" (21). ${ }^{15}$

Si a través de Proust, Mariani busca exhibir una reflexión teórica en torno a la cuestión de la renovación literaria (y la invención de una lengua), su estudio también le permite teorizar sobre el problema de la representación y el realismo, en

\footnotetext{
${ }^{14}$ La alusión resulta aún más sugestiva si se tiene en cuenta que tres años antes, en "Martín Fierro y yo" (Martín Fierro n7, del 25/7/1924), Mariani había denunciado la mediocridad del mismo Paul Morand, y cargado las tintas contra Ramón Gómez de la Serna.

15 "Marcel Proust trabaja con toda clase de material: la realidad inmediata de la minucia; y la siguiente, más trascendental. Y así podemos gustar las miles adivinaciones psicológicas y las innumerables ideas novedosas, al mismo tiempo que los personajes totalmente repujados o las escenas completas y acabadas. Para ello, Marcel Proust ha necesitado crearse su modo especial de expresión. Acaso sea el único modo de expresar su arte" (22).
} 
el que encontramos una estructura de sentimiento dada por la recurrente cuestión (en todas las publicaciones estudiadas en este trabajo) de lo introspectivo como una vía ensanchada de conocimiento de la mente humana, que se desarrollaba a través de la prosa:

El realismo y el psicologismo no consisten hoy en el uso exacto y fiel de una Kodak y un metro para fotografiar a un individuo o medirle el tamaño de su dedo meñique. Ni en el empleo de los curiosos métodos freudianos [...]. El realismo es, desde el punto de vista técnico, selección, elección, preferencia de unos detalles y el desprecio de otros. Las gentes se resisten a creer que el realismo ha superado a Zola. En Proust existe, porque es artista, esa selección de la realidad, esa preferencia de unos detalles y el desprecio de otros. (23)

Por su parte, Max Dickmann también se detiene en el carácter innovador y en los "procedimientos a primera vista complicados y hasta laberínticos" (25) de la escritura de Proust, sobre la que propone "ensayar un análisis objetivo y desapasionado" para "conocer sus valores y señalar sus defectos" (Ibid.). El joven escritor alude recurrentemente al "método", a la "técnica" y a su "método", y en los efectos concretos, corporales, de lectura. También aparece en su reflexión la cuestión de la novedad en el trabajo sobre la lengua (el señalamiento de la sintaxis) y el "carácter ilegible" atribuido a su obra, que produce un "choque, [que] deriva naturalmente-dice Dickmann- de la forma que elige Proust para escribir su obra, la cual es de una pesadez, una densidad abrumadora pero en realidad, la única que convenía a su concepción de innovador, de creador de un género literario que podríamos llamar intelectualista [...]" (26).

Si al señalar un "defecto" de Proust, dado por el tratamiento de la sexualidad $\mathrm{y}$ de un "realismo que toca los límites de la pornografia", que relaciona en parte con el "erotismo enfermizo que ha sobrevenido después de la guerra", Dickmann 
tiende hacia un tipo de argumentación "heterónoma", en el final del artículo, el balance de la obra proustiana retorna al valor de la novedad como originalidad:

Para el desarrollo de este arte tan complejo, para el desenvolvimiento de esas parcelas de vida, para descubrir todo ese universo de ficción y realidad, Proust ha necesitado de densas y largas páginas. [...] El de Proust es un arte sin antecedentes ni derivación de arte anterior alguno. [...] Por linaje de orden filosófico, moral y estético, Proust es un espíritu único, no solo en la literatura francesa, sino en la de todas las lenguas. (42)

Como se ve, este abordaje formalista de la escritura proustiana, aun cuando el crítico pone reparos moralistas (en el tratamiento proustiano de la sexualidad), es revelador del modo en que los valores específicamente literarios circularon más allá de los círculos vanguardistas, y permiten observar el grado de desarrollo específico del campo literario en los años Veinte y explican la omnipresencia de los tópicos de lo nuevo como definición de la literatura, y en relación con éste, de la técnica y la innovación formal como criterios para definirlos.

En definitiva, mientras los martinfierristas ponían en duda los "fines estéticos" de los realistas de Boedo, ellos se tomaron en serio el estudio y la exploración de nuevas posibilidades narrativas, y buscan compensar su (relativamente) escaso capital cultural (y también simbólico), leyendo en francés las novedades literarias francesas (como lo prueba no solo la lectura de Proust, sino el conocimiento del libro de Pierre Quint sobre Proust). Más aún, si seguimos la idea de Ana Porrúa que observó las "ausencias" de escritos vanguardistas europeos en la "Biblioteca" de Martín Fierro, podemos decir que Mariani y Dickmann fueron más lejos, y se animaron a leer lo nuevo. Por otra parte, los problemas que plantea el análisis de los presupuestos críticos en las lecturas de la Recherche permiten indagar sobre la modernización de la crítica literaria y evaluar la función específica de las publicaciones en ese proceso, contrastándola con el componente de actualización propio de la prensa. 
Los cambios en el discurso crítico se verifican incluso en un escritor de la generación anterior como Manuel Gálvez. En un libro de ensayos sobre literatura de 1924, dedica un capítulo a la novela proustiana, titulado "La literatura y el conocimiento. A propósito de Marcel Proust". En él también despliega el tópico de la innovación formal y en particular el "procedimiento" como base de la originalidad. Este ensayo también ilustra la estructura de sentimiento a la que me he referido más arriba, en su ponderación de los libros de Proust como "revelación maravillosa" (151) de un perfeccionamiento de la inteligencia humana, de los sentidos y de la intuición, por revelar un mayor conocimiento del misterio de la humano, de su psiquis (junto a las exploraciones de Freud sobre el subconsciente, y a las de Einstein sobre las relaciones entre los seres y las cosas) que viene así a refutar el predominio de la razón propia del positivismo, y su idea de un "Universo sin enigmas" (146). Así, en la misma línea que los jóvenes reformistas antipositivistas, Gálvez pregunta si acaso esto no implica "la afirmación tácita de la necesidad de la metafísica. Todo en el mundo es enigma” (146).

\section{Teorizaciones sobre lo nuevo a partir de Proust}

Otro rasgo recurrente en los distintos análisis de la escritura y la obra de Proust estuvo dado por teorizaciones a partir de las ideas presentes en esa obra, referidas a los efectos de la literatura sobre el orden social, manifestado a través de las convenciones, el lugar común o estereotipo, la costumbre. En este sentido, Roberto Mariani, por ejemplo, concluía, su estudio citando precisamente esa idea proustiana, para explicar el impacto de su obra. ${ }^{16}$ También encontramos esta idea

16 “Él mismo, refiriéndose al problema general, dice: 'Como toda novedad requiere indispensablemente la eliminación previa del lugar común a que estábamos acostumbrados y que se nos antojaba la realidad misma, cualquier conversación nueva, como cualquier pintura o música originales, parecerá siempre alambicada y fatigosa"” (23). Proust también lo expresó en su correspondencia, como por ejemplo, en esta carta a Paul Morand, citada por él en el número de homenaje a Proust editado en enero de 1923 por la N.R.F, y que los jóvenes porteños conocían, tal como se deduce de la referencias a críticos que colaboraron en ese número (Rivière, Crémieux, Gide, Ortega y Gasset, entre otros): "Lo que lamento mucho es ver a personas inteligentes como 
CATEDRAL TOMADA: Revista de crítica literaria latinoamericana / Journal of Latin American Literary Criticism La recepción temprana de Marcel Proust en el espacio de revistas culturales argentinas de los años veinte

del acerca del contraste entre la primera lectura como dificultosa (que perturba el hábito), y la claridad que emerge cuando el lector ingresa en su mundo en los artículos de Max Dickmann, de Juan Ramos para Verbum, de Julio Irazusta en La Nación de Buenos Aires, ${ }^{17}$ o incluso en el ensayo de Gálvez. Por último, la encontramos en varios de los críticos de Fiesta, ${ }^{18}$ en los modos en que la revista sostiene una idea la novedad asociada a la expresión de una

N... poner ante todo el gusto, o al menos lo que consideran como tal, y negar de antemano todo aquello que producirán las épocas por venir. Si Courbet, si Manet, si Renoir hubieron sido penetrados por semejante estética, hoy no tendrìamos más que a Bouguereau. Hicieron obra clásica porque hicieron obra nueva" (Hommage à Marcel Proust, p. 94).

Esta idea acerca de la extrañeza de todo arte cuando no se le puede asignar un valor previo, tiene en nuestro presente resonancias blanchotianas.

17 Julio Irazusta (1936) se detiene también en esta teoría, y a la vez en la experiencia de su descubrimiento. Me interesa citar extensamente estas ideas (que persisten en buena medida, con sus variantes, hay hoy), porque la enuncia precisamente como un aprendizaje teórico que deriva de las propias páginas de Proust sobre el arte original como disruptivo respecto del "lugar común". Irazusta recuerda que mientras leía a Proust, necesitaba acudir a otras lecturas: "Hasta acostumbrarse a su originalidad forzosa, hay que descansar de vez en cuando en las ya conocidas. Las lecturas al margen son el resuello necesario para la fatiga de habituarse al arte reciente. El arte es siempre lo nuevo, porque cada obra de real valor artístico es un mundo aparte -sua mole stansque no tiene nada que ver con los otros. Novedad que no consiste, sin embargo, en buscar la originalidad a toda costa, sino simplemente en hallarla. Una obra de arte es algo realmente tan homogéneo, de relaciones tan propias que, aun pasando por el camino de la imitación, llega a lo singular, la imitación - la escuela- no hace sino dar al artista los medios, la técnica para expresar sus intuiciones. Cada artista abre un camino que no lleva a ninguna parte, o vuelve a él. La toma de contacto es difícil con ellos, sobre todo al momento de su aparición. Proust resultaba terrible. Empezando por su lengua. El uso de todas las formas de conjugación era una de sus características [...]. La arquitectura habitual de sus frases era la siguiente: [...] esto no era nada comparado con el aspecto formalmente caótico que presentaba el conjunto de la obra. Las numerosas descripciones de pretencioso raciocinio tocante a omni re scibili, el gran desperdicio filosófico que lastraba la nueva nave literaria, hacían difícil su navegación en nuestro espíritu, mar surcado por corrientes profundas, nuestros hábitos mentales. [...]. Por el lado de la inteligencia cognoscitiva sería, no obstante, por donde el lector hallaría el pasaje hacia las novísimas intuiciones de Proust. [...] Un maravilloso analista, no sólo un simple conocedor, sino un verdadero técnico del corazón humano, surgía entre la maraña estilística de sus escritos...”. (1936: 1)

${ }^{18}$ La recepción de Proust que leemos en el proyecto editorial de Fiesta confirma otra presencia clave en la década del Veinte, que ya fue analizada por Karina Vázquez: la centralidad de las referencias a Ortega y Gasset, y también por Geraldine Rogers, para el caso de Martín Fierro. Precisamente, es a propósito de las tesis de La deshumanización del arte que uno de los colaboradores expresa diferencias con el filósofo español. Las objeciones que propone resultan sintomáticas, a mi entender, de una tensión que se aloja en el ethos religioso de la revista pues lo que no aceptan estos jóvenes no son las más osadas y cuestionadoras formas literarias sino cualquier puesta en duda de la existencia de un más allá para el espíritu que se abra a la experiencia de la literatura y las artes. Inversamente, la revista de estos jóvenes aficionados al arte y muy conocedores de las últimas manifestaciones permite constatar el valor hegemónico de lo nuevo que los lleva a buscar conjeturas para adaptar dicha creencia a la propia cultura religiosa, de la que no reniegan. 
sensibilidad emergente, y que se manifestaría en una forma inesperada, difícil de asir. Quisiera detenerme en una apropiación particular, en esta publicación, del sentido del arte nuevo según Proust ya que en base a ella se planteó la cuestión del sentido más legítimo de tradición, para una joven cultura como la nuestra. Miguel A. Benedit, una de las voces teóricas más recurrentes de Fiesta, y que venía escribiendo sobre la cuestión de la extrañeza o ajenidad que planteaba todo libro nuevo, retomó el tema de la tensión entre tradición y novedad en otro artículo titulado "Tradición y frases hechas" ( $\left.\mathrm{N}^{\circ} 6 / 7: 26-31\right)$. Allí se pregunta puntualmente qué sucede respecto de la tradición en Sudamérica, una tierra que caracteriza como carente de tradición. El artículo plantea en su inicio una ocurrencia humorística en torno a la vida, función y fortuna de las frases hechas, para mostrar que éstas pueden ser muy útiles pero no dejan de ser un obstáculo a la expresión de ideas genuinas, que se supone más complejas (Esta idea se acerca bastante a la de Proust sobre los estereotipos a los que recurren los hombres y mujeres en la conversación):

Todo eso se nos ha ocurrido a causa de una muy gastada explicación: la falta de creación artística -y científica- de los países sudamericanos es una consecuencia directa e inevitable de la falta de tradición en los países nuevos. Sería necesaria una tradición regional que al evolucionar, presentara automáticamente las condiciones favorables para la aparición de nuevas formas artísticas que fuera al mismo tiempo creadora de ambiente y transmisora de impulso. Pero la tradición no es nada de esto. Es lo que nos queda del pasado, es nuestra vista sobre el pasado. Es estática, no dinámica. Siempre existe, en mayor o menor grado, en todos los países. ( $\mathrm{N}^{\mathrm{o}}$ 6/7: 26-27)

Tras preguntarse cuál sería nuestra tradición (si la española o la criolla), y desarrollar una definición en base a una dialéctica entre estereotipo/costumbre y su dislocación o renovación, Benedit pasa a caracterizar la tradición europea: 
La tradición viene de lejos, se ha formado en el tiempo, pero cada época la ha cristalizado en un solo momento. Lo que era sucesión en el tiempo aparece al espectador como algo inerte y completamente formal. Y después de contribuir a abrir los ojos del público a una forma de belleza, lo vuelve más ciego que un topo cuando tiene que renovarse. Hay que seguirla o romper lanzas con ella. Su influencia es absorbente. Ése es el estado de cosas en Europa donde cada tendencia se hace exclusivista. El arte debe adaptarse a un molde determinado: lo demás queda afuera. En cambio en América, podemos apreciar, libres de influencia previa, a la totalidad del arte. Podemos apreciar simultáneamente a Andreieff, Crommelink, Musset y Jules Romains. Con afinado sentido artístico, podemos, suprimiendo cronologías, nacionalidades y demás factores secundarios, contemplar a los más distintos y lejanos maestros en el mismo plano superior estético. (29)

Frente a este diagnóstico, lo que se esboza es un programa universalista que, haciendo de necesidad, virtud, convierte la carencia en libertad. Estamos ante una formulación temprana de algunas soluciones planteadas por Borges en "El escritor argentino y la tradición” (1957 [1953]). Benedit argumenta así que:

La cultura universal puede reemplazar con creces a la propia tradición artística, no desalojándola sino restándole su carácter exclusivo [...]. Cuando se estudia las interferencias y fluctuaciones, cuando se observa la influencia recíproca de franceses e ingleses entre los escritores europeos [el éxito de Joyce en Francia; el de Proust en los países de habla inglesa], ¿A qué deplorar la falta de tradición artística cuando hay tantas a nuestro alcance?, ¿Por qué acusar tanto a la falta de tradición propia cuando tenemos a nuestra disposición una escuela superior a la de Atenas, formada por todos los genios del mundo? [...] ¿Y qué mejor tradición puede tener un artista que la por él mismo preferida? Es ventaja positiva 
la libertad de escoger de acuerdo con las tendencias naturales. Las únicas influencias trascendentales son las impuestas por la admiración. El arte libre de trabas y la sinceridad desnuda de la literatura moderna son la suma de todas las tendencias artísticas anteriores. Será paradójico para los que se empecinan en lo vetusto, pero es evidente que la verdad artística resplandece en los momentos actuales; desde Shakespeare salva la historia a pasos agigantados, marcando jalones que se llamaron Molière, Stendhal, para primar en la literatura del último medio siglo. Los temas del arte heroico han sido abandonados para tratar los que aquellos ocultaban: el estudio del hombre y sus afanes. ¿Qué mejor tradición que ésta, de hombres que se muestran por entero? Todos podrían ostentar el mismo viejo lema socrático: 'conócete a ti mismo'. (31)

De este modo, quedan anudados el valor de la renovación permanente como ley inexorable de la cultura, a un sentido de la novedad que se entendía como superador, y necesariamente superior a las ideas del pasado. Con ingenio, el autor encuentra un modo de insertarse en la tradición universal afirmando el sentido de una literatura de introspección ("el estudio del hombre y sus afanes"; "conócete a ti mismo") como la forma necesaria de la modernidad, para que pueda existir una literatura local.

\section{Conclusiones}

Tal como he intentado analizar en este trabajo, las referencias a la novela de Marcel Proust fueron mucho más allá de la información sobre la actualidad literaria. En casi todos los casos, en efecto, la inclusión de colaboraciones no respondió a un fin exclusivamente informativo, de difusión de la actualidad, excepto en La Nación 
o acaso en Nosotros, ${ }^{19}$ la principal representante de la generación anterior; la extrañeza de la escritura de Proust suscitó en el Río de La Plata, al menos, una curiosidad y un entusiasmo que fue colectivo, en el sentido en que fue adoptado por grupos de amigos, o por jóvenes escritores nucleados en formaciones que encontraron en él una síntesis de la "nueva sensibilidad" (en los términos de Ortega y Gasset), que se expresaba, o se estructuraba en varias dimensiones (narrativa y literaria; filosófica y psicológica). La Revista de Filosofía de José Ingenieros, que ocupaba también una posición dominante en el campo de revistas y dedicaba pocos artículos a cuestiones literarias, también intervino sobre Proust, lo cual indica el carácter de fenómeno cultural que tuvo su circulación en Buenos Aires. Esta temprana lectura de Proust, y de las producciones críticas sobre su obra publicada en Francia y en España (principalmente en la Revista de Occidente de Ortega y Gasset) también se advierte en algunos recuerdos de escritores y en la organización de conferencias que se desarrollaban en ámbitos muy variados de la cultura de Buenos Aires, pero se articuló centralmente en las publicaciones que animaban los jóvenes vanguardistas, aspirantes a escritor, o reformistas: Martín Fierro (192427), Fiesta (1927-28), Libra (1929), Verbum (1912-37), Valoraciones (1923-28), Síntesis (1927-30). En este sentido, el análisis de los sumarios de dichas publicaciones, e incluso de los programas estéticos de alguna de ellas, revela que muy tempranamente tanto Proust como la crítica europea (española y francesa) formaron parte, por un lado, de la biblioteca los jóvenes escritores nacidos alrededor de 1900, vinculados a la vanguardia martinfierrista y a la literatura social de Boedo. Pero, por otro lado, Proust también aparecía en la biblioteca de los universitarios, que participaron del clima de renovación intelectual en el proceso abierto por el movimiento de la reforma universitaria, especialmente en sus expresiones antipositivistas que combinaron el idealismo y el esteticismo (Bustelo). Todo este conjunto diverso de actores no solo leyó a Proust sino que escribió sobre

${ }^{19}$ En esta revista, el nombre de Proust aparece mencionado por primera vez en 1923 en la "Crónica de la vida intelectual francesa" por Francis de Miomandre (quien ya había hablado sobre él en su columna para La Nación del), y no recibe una valoración positiva de parte de uno de sus directores, Roberto Giusti, se cumple con el compromiso de informar sobre las actualidades literarias. 
sus novelas (es decir, lo estudió) a medida que iban apareciendo, incluso en su edición francesa. Es más, la relación con la obra Proust se caracterizó por su estudio, es decir por una apropiación activa de la obra y de la lectura de bibliografía reciente sobre él. Podría decirse que la lectura de los tomos de En busca del tiempo perdido constituyó una marca generacional, omnipresente entre los jóvenes aspirantes a escritor, profesores o diletantes, graduados universitarios que participaron de la renovación de la década del veinte.

En especial, entre estos jóvenes intelectuales a quienes Oscar Terán (208) caracterizó como "modernos intensos", la lectura de Proust significó una vía para desarrollar criterios críticos nuevos, acordes con la complejización de las experiencias culturales y a la democratización del acceso a la cultura. Así, hemos visto aparecer recurrentemente, por un lado, un interés por indagar en el "método Proust" y en las posibilidades de la lengua literaria y por otro lado, el desarrollo de una reflexión teórica en torno a lo nuevo y sus efectos -en términos de un ensanchamiento epistemológico del mundo- que traducían ideas emergentes según las cuales la literatura constituía algo más que el cultivo de lo bello, en tanto podía ofrecer formas de conocimiento alternativas e inesperadas.

\section{Bibliografía}

AAVV "Proust en América". Libra 1, (invierno 1929): 87-88.

. Fiesta (1927-1928). Buenos Aires.

Biagini, Hugo E. "La revista Verbum y el entramado reformista".

AMÉRICALEE. El portal de publicaciones latinoamericanas del siglo XX, 2017. Web. www.americalee.cedinci.org. 
Bosoer, Sara. La vanguardia plebeya de Nicolás Olivari: Mercado, lengua y literatura (Tesis de posgrado). La Plata: Facultad de Humanidades y Ciencias de la Educación /UNLP, 2012. Web. http://www.memoria.fahce.unlp.edu.ar/tesis/te.765/te.765.pdf. Fecha de consulta: 20/10/2017.

Bustelo, N. La reforma universitaria desde sus grupos y revistas: Una reconstrucción de los proyectos y las disputas del movimiento estudiantil porteño de las primeras décadas del siglo XX (1914-1928) (Tesis de posgrado). La Plata: Facultad de Humanidades y Ciencias de la Educación, UNLP, 2015. Disponible en: http://www.memoria.fahce.unlp.edu.ar/tesis/te.1307/te.1307.pdf. Fecha de consulta: 13/10/2018

Candiano, Leonardo y Lucas Peralta. Boedo. Orígenes de una literatura militante. Buenos Aires: Ediciones del CCC. Floreal Gorini, 2007.

Dickmann, Max. “Aspectos de la novela”. Síntesis 30 (noviembre 1929). . "Por el camino de Proust". Nosotros, a. XXI, t. 66 (1927): 24-42.

Gálvez, Manuel. "La literatura y el conocimiento. A propósito de Marcel Proust". El espíritu de la aristocracia y otros ensayos. Buenos Aires: Agencia General de Librería y Publicaciones, 1924.

García Cedro, Gabriela. Boedo y Florida. Las vanguardias argentinas en los años del radicalismo clásico. Filo: UBA, tesis, 2012. Web. Fecha de consulta: julio de 2018.

Guy, Alain. "Le bergsonisme en Amérique Latine”. Caravelle 1. Web. http://www.persee.fr/web/revues/home/prescript/article/carav_01847694_1963_num_1_1_1071. Fecha de consulta: 25/11/2017.

Irazusta, Julio. "Proust ayer y hoy". La Nación, Supl. Artes y Letras, 22/11/1936:1.

Lafleur, H. R., Provenzano, S. D. y Alonso, F. P. Las revistas literarias argentinas: 1893-1960. Buenos Aires: Ediciones Culturales Argentinas, 1962. 
Mariano, Roberto. "Introducción a Marcel Proust". Nosotros, a. XXI, t. 66 (1927): 17-23.

Morand, Paul; H.C. (Trad.). “Oda a Proust”. Martín Fierro 4 (mayo de 1924).

Ortega y Gasset, José. "Le temps, la distance et la forme chez Proust". Hommage à Proust. París: La Nouvelle Revue Française 112 (1923). . La rebelión de las masas. Madrid: Espasa-Calpe, 1937. . La deshumanización del arte y otros ensayos estéticos. 1925. Madrid: Revista de Occidente1958.

Pinto, Mario. "Variaciones sobre Marcel Proust". Síntesis, a. II, 17 (octubre 1928): 215-219.

Ponce, Aníbal. "La sensación olfativa en Marcel Proust”. 1925 [Revista de filosofía]. Estudios de psicología. Buenos Aires, El Ateneo, 1941.

Porrúa, Ana. "La revista Martín Fierro (1924-1927): una vanguardia en proceso". El vendaval de lo nuevo. Literatura y cultura en la Argentina Moderna entre España y América Latina (1880-1930). Chicote, Gloria y Miguel Dalmaroni, editores. Rosario: Beatriz Viterbo Editora, 2007. 129-148.

Proust, Marcel. Du côté de chez Swann. 1913. París: Gallimard, col. Folio, 1988. . À la recherche du temps perdu. París: Quarto/Gallimard, 1999.

Ramos, Juan P. “Marcel Proust”. Verbum 66 (septiembre 1926): 237-250.

Ruvituso, Clara. Diálogos existenciales. La filosofía alemana en la Argentina peronista (1946-1955). Vervuert: Iberoamericana, 2015.

Rodríguez, Fernando. “Inicial, Sagitario y Valoraciones. Una aproximación a las letras y la política de la nueva generación americana”. La cultura de un siglo. América Latina en sus revistas. Saúl Sosnowski, editor. Buenos Aires: Alianza, 1999.

Rogers, Geraldine "La isla del arte martinfierrista". Anclajes, XIV, 14 (2010). Ruvituso, Clara. Diálogos existenciales. La filosofía alemana en la Argentina peronista (1946-1955). Vervuert: Iberoamericana, 2015.

Sapiro, Gisèle. La guerre des écrivains. 1940-1953. Paris: Fayard, 1999. 
Sarlo, Beatriz. Una modernidad periférica: Buenos Aires 1920 y 1930. Buenos Aires: Nueva, 2003.

Sosa, Jimena. "La recepción de Bergson en Argentina. La mediación española y las lecturas en la generación de 1910”. Mimeo. 2018

Terán, Oscar. "Lección 7. Democracia, guerra y 'nueva sensibilidad'. José Ingenieros y Leopoldo Lugones (1914-1930)". Historia de las ideas en la Argentina. Buenos Aires: Siglo XXI, 2008. 191-226.

Vázquez, Karina. "Intelectuales y política. La “nueva generación” en los primeros años de la Reforma Universitaria". Prismas. Revista de Historia Intelectual 4 (2000).

Williams, Raymond. Marxismo y literatura. Madrid: Península, 1980. 